Herzschr Elektrophys 2018 $29: 24-29$ https://doi.org/10.1007/s00399-017-0545-8 Received: 24 October 2017

Accepted: 24 November 2017

Published online: 5 January 2018

(c) Springer Medizin Verlag GmbH, ein Teil von Springer Nature 2018

CrossMark

\title{
Franziska Schneider-Warme
}

Institute for Experimental Cardiovascular Medicine, University Heart Center, Medical Center - University of Freiburg, and Faculty of Medicine, University of Freiburg, Freiburg, Germany

\section{The power of optogenetics}

\section{Potential in cardiac experimental and clinical electrophysiology}

This short review provides a general

One major goal in current biomedical research is to understand how molecular and cellular activities interrelate to shape tissue, organ and ultimately whole-body function. By combining the spatiotemporal precision of optical technologies with the specificity of modern genetics, optogenetics provides a unique approach to functionally dissect biological processes across multiple scales.

In optogenetics, photoreceptor proteins-often originating from simple organisms such as halobacteria, unicellular algae or marine jellyfish-are introduced to the cells of interest to optically monitor or modulate cellular behaviour (• Fig. 1). To do so, the protein-encoding genes are cloned into engineered DNA vectors that ensure target cell-specific expression, usually using suitable DNA promoters. A number of techniques have been developed to deliver the DNA vectors into the target cells, including electroporation of cells, liposome-mediated transfection and viral gene delivery. Finally, genetically modified cells can be optically stimulated, e. g. short light pulses can be applied to elicit action potential firing in neurons or myocytes that express lightgated depolarizing ion channels. According to the wider definition of optogenetics formulated by Gero Miesenböck in 2009 [1], the optogenetic toolbox encompasses actuator proteins such as light-activated ion transporters and photoactivated enzymes that are used to control cellular activity with light, and light-emitting sensor proteins allowing to optically report cellular states such as intracellular $\mathrm{Ca}^{2+}$ levels, $\mathrm{pH}$ and transmembrane voltage [1] . introduction to the optogenetic methodology and gives selected examples of cardiac applications, both for basic research and with potential clinical relevance.

\section{Brief history of optogenetics}

First optogenetic experiments date back to 1988, when Khorana et al. [2] used a photoreceptor protein, bovine visual rhodopsin, to activate inward-directed (depolarizing) currents in Xenopus oocytes upon blue-light activation. Following a similar strategy, Zemelman et al. [3] established an optogenetic system to depolarize cultured hippocampal neurons by co-expression of Drosophila rhodopsin with two interacting proteins. The breakthrough of optogenetics as a technique coincided with the discovery of channelrhodopsins (ChRs) [4, 5], light-gated ion channels serving as primary photoreceptor proteins in green algae. In cation-selective ChRs, light absorption by the cofactor all-trans retinal-a derivative of vitamin $\mathrm{A}$-causes conformational changes within the protein that lead to a transient opening of the channel, allowing trans-membrane flux of $\mathrm{H}^{+}, \mathrm{Na}^{+}$and $\mathrm{Ca}^{2+}$ [6]. Based on these light-activated currents, ChRs can be used to depolarize cells of interest, which was soon applied to optically trigger action potentials in neurons [7]. The optogenetic toolbox has since been extended by light-driven chloride and proton pumps $[8,9]$, which allow optical inhibition of neuronal activity by hyperpolarization, and by anion ChRs $[10,11]$, which shunt the membrane potential to the reversal potential for $\mathrm{Cl}^{-}$ (- Fig. 2a).

In parallel to the development of optogenetic actuators, fluorescent reporter proteins sensitive to intra- and extracellular parameters such as $\mathrm{pH}$, ion concentrations and membrane voltage have been generated (• Fig. 2b; [12-14]). These allow for cell-type specific interrogation of cellular states in complex biological tissue such as the brain and the heart, which had not been feasible using classical dye-based imaging or electrophysiological recordings.

\section{Optogenetics at heart}

The optogenetic paradigm was first transferred to cardiac research about ten years ago. In 2010, Bruegmann et al. [15] reported a transgenic mouse model expressing channelrhodopsin-2 (ChR2) in the heart. In these mice, blue-light pulses triggered action potentials in cardiac myocytes, allowing the heart to be paced by illuminating the right atrium, the ventricles or the septum. In the same year, Arrenberg et al. [16] generated zebrafish models expressing either ChR2 or the light-driven chloride pump NpHR in cardiomyocytes, so that the hearts could be optically paced or transiently arrested with blue and orange light, respectively. Local illumination patterns generated with a digital micro-mirror device were used to identify the pacemaker region at different developmental stages and to induce atrioventricular (AV) block. This study exemplifies how the full potential of optogenetics can only be exploited when combining spatially defined illumination patterns with fast high-resolution imag- 


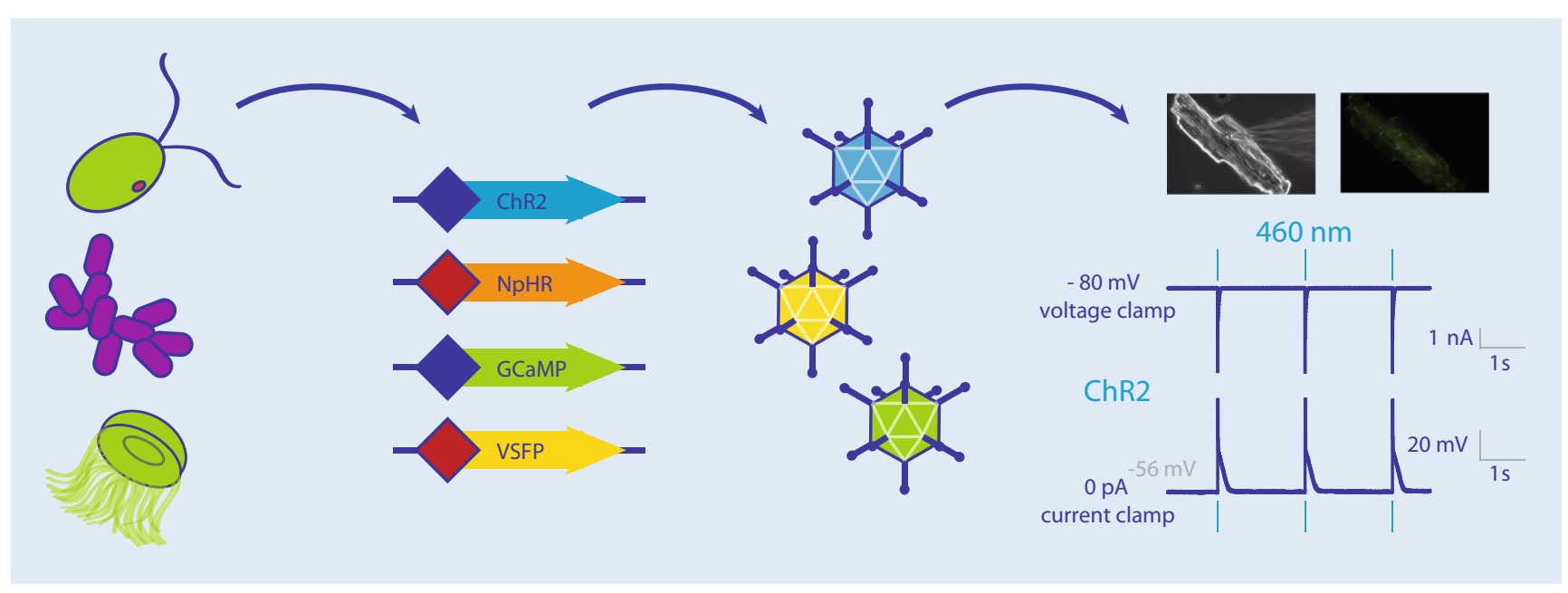

Fig. $1 \Delta$ Optogenetic principle. Photoreceptors and fluorescent proteins often occur in simple organisms such as halobacteria (e. g. bacteriorhodopsin and the chloride pump NpHR), motile green algae (e.g. channelrhodopsin-2, ChR2) or jellyfish (e. g. green fluorescent protein, GFP). For heterologous expression, the respective protein-encoding genes are cloned into DNA vectors with cell-type specific promoter sequences. These DNA vectors can be delivered to the target cells using engineered DNA viruses as shuttles. Genetically modified cells can be stimulated with light. For example, ChR2 expressed in murine cardiomyocytes (see picture of fluorescently labelled ChR2 in an isolated myocyte) mediates depolarizing photocurrents following blue-light stimulation, as can be seen in whole-cell patch clamp recordings. These photocurrents reliably trigger action potentials. GCaMP genetically encoded calcium indicator based on GFP, calmodulin and the interacting M13 peptide; $\mathrm{NpHR}$ halorhodopsin from Natronomonas pharaonis; VSFP voltage-sensitive fluorescent protein

ing techniques, for example by using selective plane illumination microscopy (SPIM), also referred to as light sheet microscopy [16].

Similar to neurosciences, fluorescent reporter proteins have been applied to follow $\mathrm{Ca}^{2+}$ and voltage dynamics in cardiac cells, and also to visualize changes in second messenger concentrations and enzyme activity. Tallini et al. [17] created a mouse model conditionally expressing the genetically encoded $\mathrm{Ca}^{2+}$ indicator GCaMP2 in cardiomyocytes, allowing $\mathrm{Ca}^{2+}$ transients to be measured from different heart regions in vivo. Additionally, embryonic development of the $\mathrm{AV}$ node was followed by imaging $\mathrm{Ca}^{2+}$ waves in open-chested embryos. This allowed functional identification of an AV canal with considerably slowed conduction that transiently appeared between days 10 and 13.5 of mouse embryonic development. In a more recent study, Shang et al. [18] used the fast $\mathrm{Ca}^{2+}$ indicator GaMP6f, targeted to the dyadic space (here: the nanoscopic volume of cytosol between the plasma membrane/t-tubular membrane and the sarcoplasmic reticulum), to image nano-domain $\mathrm{Ca}^{2+}$ sparks in isolated cardiomyocytes from rat. In addition to $\mathrm{Ca}^{2+}$ waves, membrane volt- age can be imaged using voltage-sensitive fluorescent proteins (VSFPs) including the FRET sensor VSFP2.3. Expressing VSFP2.3 under control of the myocytespecific $\alpha$-myosin heavy chain promoter, cardiac myocyte-specific voltage dynamics were recorded at high spatial resolution, both ex vivo (Langendorff-perfused hearts) and in vivo (using a fibre optic system for light and camera coupling) [19]. In addition to $\mathrm{Ca}^{2+}$ and voltage sensors, fluorescent reporter proteins sensitive to protein kinase A activity and cellular cAMP/cGMP levels have been developed and applied to disentangle subcellular signalling cascades in cardiomyocytes [20-22]. Up to now, most cardiac optogenetic studies have focussed on technical development of probes, gene delivery and instrumentation, and we await application of these tools to answer questions in basic cardiac research in the very near future.

\section{Optogenetics to study heterocellular coupling}

Optogenetics is a powerful technique for deciphering cell-type specific behaviour, either by local illumination of the cells of interest, or by use of promoter sys- tems that drive gene expression of actuators and sensors in the target cells only. In this regard, optogenetic approaches are useful to analyse heterocellular interactions in the heart, which have been suggested to be of importance for cardiac function, but are difficult to investigate with conventional cell-type unspecific techniques such as microelectrode-based electrophysiology recordings or dye-based optical mapping of membrane voltage. In the first study to tackle myocyte-nonmyocyte coupling using optogenetics in cardiac tissue in situ, Quinn et al. [23] specifically expressed the voltage sensor VSFP2.3 in cardiac nonmyocytes. Using optical voltage mapping, they found action-potentiallike membrane depolarization in nonmyocytes of scar border tissue, indicating electrotonic coupling of these nonmyocytes to myocytes on a beat-to-beat basis. Using the same targeting strategy, which had worked to specifically express VSFP in nonmyocytes only, resulted in unspecific ChR2 expression in both myocytes and nonmyocytes [24]. However, ChR2 has been successfully expressed specifically in cardiac resident macrophages. Interestingly, activating a light-gated channel in macrophages fa- 
cilitated AV conduction, supporting the idea that resident macrophages can also be electrically coupled to myocytes via gap junctions [25]. These experiments highlight that nonexcitable cell populations can impact cardiac electrophysiology by functionally coupling to myocytes. Whereas such coupling was proposed decades ago [26], cell-type specific optogenetic interrogations now support quantitative investigations into heterocellular electrotonic coupling, and its relevance for cardiac function in the intact organ.

\section{Cardiac applications with potential clinical relevance}

Pioneering cardiac optogenetic experiments demonstrated ChR2-mediated optical pacing $[15,16]$. Light-activated pacing differs from external electrical stimulation, used in classic pacemakers, in two key points. (1) Optical pacing can be confined to pacemaker cells only, minimizing side effects caused by electrical stimulation of neighbouring myocardium and nonexcitable cells. This would require ChR expression targeted to pacemaker cells, e. g. using adeno-associated viruses in combination with a specific promoter for transcriptional activation, such as the HCN4 promoter. (2) ChR2-mediated pacing uses the electrochemical gradient generated by the cells-i.e. the intrinsic battery of pacemaker cells-and the depolarizing ChR current triggers opening of endogenous voltage-gated $\mathrm{Ca}^{2+}$ channels (and cell-type dependent also $\mathrm{Na}^{+}$ channels) resulting in action potential generation. As a result, optical pacing may offer an alternative for rhythm control with high specificity and low external energy demand.

ChR activation has recently been used to terminate ventricular arrhythmias [27-29]. Using different ChR variants (blue-light activated ChR2 or a ChR variant with red-shifted absorption, ReaChR) and different spatiotemporal illumination patterns ( $1 \mathrm{~ms}$ to $1 \mathrm{~s}$ light pulses; local, patterned or global ventricular light stimulation), these studies concluded that optical depolarization is very effective for arrhythmia termination in mouse and rat hearts. Notably,

Herzschr Elektrophys 2018 $29: 24-29$ https://doi.org/10.1007/s00399-017-0545-8

(c) Springer Medizin Verlag GmbH, ein Teil von Springer Nature 2018

\section{F. Schneider-Warme}

\section{The power of optogenetics. Potential in cardiac experimental and clinical electrophysiology}

Abstract

Optogenetics is an emerging, interdisciplinary research area which combines genetic and optical technologies to steer and monitor specific biological processes. To this end, lightactivated proteins, so-called optogenetic actuators, or fluorescent sensor proteins are genetically targeted to the cells of interest. Light activation can then be used to modulate or record cellular behaviour with high spatiotemporal precision. In cardiac research, optogenetic approaches have been used to unravel heterocellular electrotonic interactions, both in vitro and in situ.
Pioneering optogenetic studies with potential relevance for clinical electrophysiology include light-controlled pacing experiments and optical defibrillation studies. However, despite successful implementation in mouse models, clinical applications are not feasible to date; these will require major advances in gene therapy and in optical techniques.

\section{Keywords}

Light-activated proteins - Channelrhodopsins . Heterocellular electrotonic interactions . Pacing · Defibrillation

\section{Die Stärke der Optogenetik. Möglichkeiten für die experimentelle und klinische kardiale Elektrophysiologie}

\section{Zusammenfassung}

Optogenetik ist ein junges, interdisziplinäres Forschungsgebiet, in dem genetische und optische Methoden kombiniert werden, um biologische Prozesse gezielt zu steuern oder zu beobachten. Dafür werden lichtaktivierte Proteine, sog. optogenetische Aktuatoren, oder fluoreszierende Sensorproteine spezifisch in Zellen eines bestimmten Typs eingebracht. Die Beleuchtung der Zielzellen erlaubt es dann, deren Verhalten zu modulieren oder Veränderungen zellulärer Parameter optisch zu verfolgen, und zwar mit hoher zeitlicher und räumlicher Auflösung. In der Herzforschung wurden optogenetische Ansätze bereits angewendet, um die elektrischen Interaktionen zwischen verschiedenen Zelltypen zu untersuchen, sowohl in Zellkulturexperimenten (in vitro) als auch in intakten Herzpräparationen (in situ). Erste optogenetische Experimente mit potenzieller Relevanz für die klinische Elektrophysiologie beschäftigten sich mit lichtkontrollierten Schrittmachern sowie optischen Defibrillatoren. Trotz erfolgreicher Umsetzung dieser Konzepte in Mausmodellen, ist die klinische Realisierung optogenetischer Therapien heute noch nicht praktikabel und bedarf technologischer Weiterentwicklungen in der Gentherapie sowie im Bereich von klinisch einsetzbaren optischen Komponenten.

\section{Schlüsselwörter}

Lichtaktivierte Proteine · Kanalrhodopsine $\cdot$ Heterozelluläre elektrotonische Wechselwirkungen - Schrittmacher . Defibrillator computational modelling predicts that light-mediated depolarization can terminate human infarct-related ventricular tachycardia; however, this would require a red-light activatable $\mathrm{ChR}$ to ensure transmural depolarization (red light can penetrate deeper into cardiac tissue due to reduced absorption and scattering) [27]. In future, optogenetic arrhythmia termination might offer a pain-free alternative to electrical defibrillators applying unspecific, high-energy electric shocks.
Beyond optical pacing and defibrillation, optogenetic actuators and fluorescent sensors have been applied to analyse the electrophysiological characteristics of patient-derived cells and their specific drug responses [30-32]. To do so, primary cardiomyocytes or human stem cell derived cardiomyocytes were virally transduced to express spectrally separated ChRs, $\mathrm{Ca}^{2+}$ and voltage reporter proteins. This enabled all-optical, contactless screening of small molecules to evaluate their effect on patient-specific 


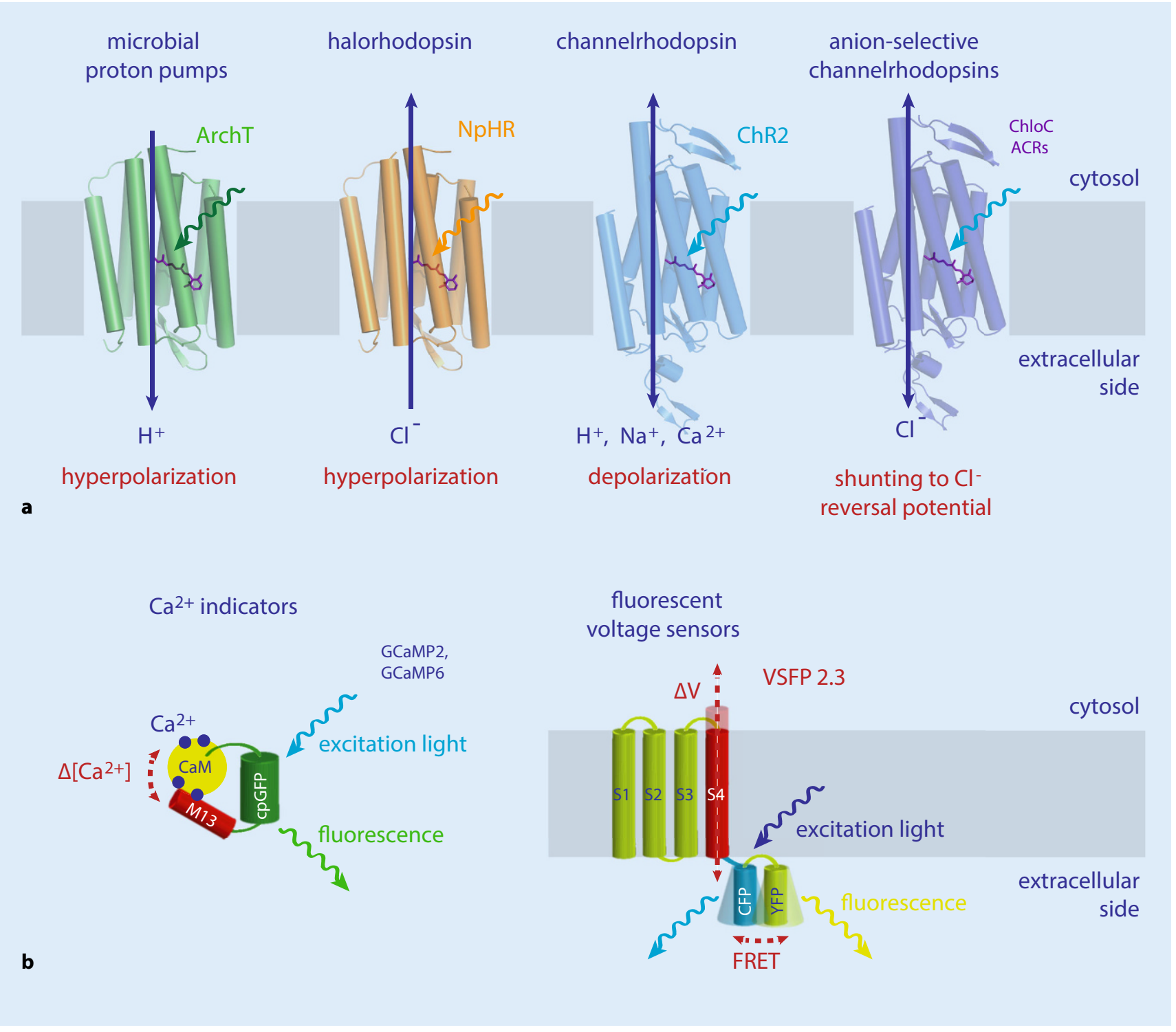

Fig. $2 \Delta$ Overview of commonly used optogenetic probes. a Optogenetic actuators include light-activated proton and chloride pumps that actively transport ions against the electrochemical gradient across the plasma membrane, leading to membrane hyperpolarization. Examples include the proton-pumping archaerhodopsin from the Halorubrum strain TP009 $(\mathrm{Arch} T)$ and the chloride-transporting halorhodopsin from Natronomonas pharaonis ( $\mathrm{NpHR}$ ). In contrast, channelrhodopsins (ChRs) are passive ion channels, gated by light stimulation. Cation-selective ChRs such as channelrhodopsin-2 from Chlamydomonas reinhardtii (ChR2) are permeable for $\mathrm{H}^{+}, \mathrm{Na}^{+}$and $\mathrm{Ca}^{2+}$ and trigger depolarizing currents if activated in resting cardiomyocytes. Anion-selective ChRs (e.g. the engineered chloride-conducting channelrhodopsin, ChloC, and natural anion channelrhodopsins, ACRs) conduct $\mathrm{Cl}^{-}$, thereby shunting the membrane potential to the reversal potential for $\mathrm{Cl}^{-}$. b Optogenetic reporters include genetically encoded $\mathrm{Ca}^{2+}$ indicators that are sensitive to changes in the $\mathrm{Ca}^{2+}$ concentration. In so-called GCaMPs, this is realized by a circularly permutated green fluorescent protein (cpGFP), framed by calmodulin $(C a M)$, and the $\mathrm{M} 13$ peptide. $\mathrm{Ca}^{2+}$ binding to calmodulin induces binding to M13, which in turn triggers conformational changes in the cpGFP that lead to increased green fluorescence. Fluorescent voltage sensors, on the other hand, change their fluorescence upon changes in membrane voltage. In voltage-sensitive fluorescent proteins (VSFPs), this is realized by linking the voltage-sensing domain of a phosphatase to a pair of fluorescent proteins. Changes in trans-membrane potential lead to conformational changes in the voltage sensor which are propagated to the fluorescent proteins. These change their orientation to one-other, resulting in an altered efficiency of Förster resonance energy transfer (FRET) between the fluorescence donor (e. g. cyan fluorescent protein, CFP) and the acceptor (e.g. yellow fluorescent protein, YFP), and thus in a change in the ratio of light intensities, emitted from the two fluorochromes 
action potential characteristics, paving the way towards fast, high-throughput drug screening to develop personalized treatment of cardiac diseases (so-called precision medicine).

\section{Outlook and future challenges}

During almost a decade of research, cardiac optogenetics has proven its utility for tackling basic questions of experimental electrophysiology such as the importance of heterocellular coupling for cardiac function. Moreover, optogenetics may be a method for clinical electrophysiology potentially useful for pacing, arrhythmia termination and patientspecific drug testing. However, clinical application of optogenetics still requires major technological advances, including the following:

- Gene delivery needs further improvement to minimize the presence of neutralizing antibodies and cellular immune responses directed against viral shuttles and/or the genetically modified cells, and to ensure high transgene expression levels in the target cells only [33].

- Side effects of transgene expression and photoreceptor dark activity have to be excluded. As an example, cardiac expression of the $\mathrm{Ca}^{2+}$ sensor GCaMP has been shown to induce hypertrophy as a result of calmodulin motif overexpression, which could be prevented by using an inducible gene expression system [17].

- In vivo optogenetics requires flexible, biocompatible light sources. Depending on the application, light delivery may occur via optical fibres coupled to lasers or light-emitting diodes for epicardial illumination, catheterbased light guides for endocardial illumination, or implantable microprocessor-controlled illumination sources [34].

Once these technical challenges can be addressed, optical therapies may become feasible alternatives for heart rhythm control in patients.

\section{Conclusion}

- In optogenetics, light-activated proteins and fluorescent sensor proteins are used to steer or monitor cellular behaviour.

- Upon illumination ChRs and light-activated ion pumps drive depolarizing or hyperpolarizing membrane currents, thereby activating or inhibiting cardiac activity.

- Genetically encoded fluorescent reporters allow visualization of voltage and $\mathrm{Ca}^{2+}$ dynamics in specific cell populations, offering tools to study heterocellular signalling in intact cardiac tissue.

- In future, optogenetics may be clinically applied for rhythm control and patient-specific drug screening. This will require major advances in gene delivery methods, optogenetic probes and light sources.

\section{Corresponding address}

\section{Dr. F. Schneider-Warme}

Institute for Experimental Cardiovascular Medicine, University Heart Center, Medical Center - University of Freiburg, and Faculty of Medicine, University of Freiburg Elsässerstr. 2q, 79110 Freiburg, Germany franziska.schneider@universitaetsherzzentrum.de

Acknowlegdement. I thank all members of the Institute for Experimental Cardiovascular Medicine for critical discussion of the manuscript. This work was supported by the German Research Foundation (SPP1926, SCHN 1486/1-1).

\section{Compliance with ethical guidelines}

Conflict of interest. F. Schneider-Warme declares that she has no competing interests.

This article does not contain any studies with human participants or animals performed by any of the authors.

\section{References}

1. Miesenböck G (2009) The optogenetic catechism. Science 326:395-399

2. Khorana HG, Knox BE, Nasi Eetal (1988) Expression of a bovine rhodopsin gene in Xenopus oocytes: demonstration of light-dependent ionic currents. Proc Natl Acad Sci U SA 85:7917-7921
3. Zemelman BV, Lee $\mathrm{GA}, \mathrm{Ng} \mathrm{M}$, Miesenböck $\mathrm{G}$ (2002) Selective photostimulation of genetically chARGed neurons. Neuron 33:15-22

4. Nagel G, Ollig D, Fuhrmann M et al (2002) Channelrhodopsin-1: a light-gated proton channel in green algae. Science 296:2395-2398

5. Nagel G, Szellas T, Huhn W et al (2003) Channelrhodopsin-2, a directly light-gated cationselective membrane channel. Proc Natl Acad Sci U SA 100:13940-13945

6. Schneider F, Grimm C, Hegemann P (2015) Biophysics of channelrhodopsin. Annu Rev Biophys 44:167-186

7. Boyden ES, Zhang F, Bamberg Eetal (2005) Millisecond-timescale, genetically targeted optical control of neural activity. Nat Neurosci 8:1263-1268

8. Gradinaru V, Thompson KR, Deisseroth K (2008) eNpHR:a Natronomonas halorhodopsin enhanced for optogenetic applications. Brain Cell Biol 36:129-139

9. Han X, Chow BY, Zhou H et al (2011) A high-light sensitivity optical neural silencer: development and application to optogenetic control of nonhuman primate cortex. Front Syst Neurosci 5:18. https://doi.org/10.3389/fnsys.2011.00018

10. Wietek J, Wiegert JS, Adeishvili N et al (2014) Conversion of channelrhodopsin into a light-gated chloride channel. Science 344:409-412

11. Govorunova EG, Sineshchekov $O A$, Janz $R$ et al (2015) NEUROSCIENCE. Natural light-gated anion channels: a family of microbial rhodopsins for advanced optogenetics. Science 349:647-650

12. Miyawaki A, Llopis J, Heim Retal (1997) Fluorescent indicators for $\mathrm{Ca} 2+$ based on green fluorescent proteins and calmodulin. Nature 388:882-887

13. Siegel MS, IsacoffEY (1997) A genetically encoded optical probe of membrane voltage. Neuron 19:735-741

14. Miesenböck G, De Angelis DA, Rothman JE (1998) Visualizing secretion and synaptic transmission with $\mathrm{pH}$-sensitive green fluorescent proteins. Nature 394:192-195

15. Bruegmann T, Malan D, Hesse $M$ et al (2010) Optogenetic control of heart muscle in vitro and in vivo. Nat Methods 7:897-900

16. Arrenberg $A B$, Stainier DYR, Baier $H$, Huisken J (2010) Optogenetic control of cardiac function. Science 330:971-974

17. Tallini YN, Ohkura M, Choi B-R et al (2006) Imaging cellular signals in the heart in vivo: Cardiac expression of the high-signal $\mathrm{Ca}^{2+}$ indicator GCaMP2. Proc Natl Acad SciU SA 103:4753-4758

18. Shang W, Lu F, Sun T et al (2014) Imaging $\mathrm{Ca}^{2+}$ nanosparks in heart with a new targeted biosensornovelty and significance. Circ Res 114:412-420

19. Liao CM-L, de Boer T, Mutoh Het al (2015) Sensing cardiac electrical activity with a cardiac myocyte targeted optogenetic voltage indicator. Circ Res 117:401-412

20. Liu S, Zhang J, Xiang YK (2011) FRET-based direct detection of dynamic protein kinase a activity on the sarcoplasmic reticulum in cardiomyocytes. Biochem Biophys Res Commun 404:581-586

21. Gotz KR, Sprenger JU, Perera RK et al (2014) Transgenic mice for real-time visualization of cGMP in intact adult cardiomyocytes. Circ Res 114:1235-1245

22. Yaniv Y, Ganesan A, Yang D et al (2015) Realtime relationship between PKA biochemical signal network dynamics and increased action potential firing rate in heart pacemaker cells. J Mol Cell Cardiol 86:168-178 
23. Quinn TA, Camelliti P, Rog-Zielinska EA et al (2016) Electrotonic coupling of excitable and nonexcitable cells in the heart revealed by optogenetics. Proc Natl Acad Sci U S A 113:14852-14857

24. Johnston CM, Rog-Zielinska EA, Wülfers EM et al (2017) Optogenetic targeting of cardiac myocytes and non-myocytes: tools, challenges and utility. Prog Biophys Mol Biol 130:140-149

25. Hulsmans M, Clauss S, Xiao L et al (2017) Macrophages facilitate electrical conduction in the heart. Cell 169:510-522

26. Kohl P, Kamkin AG, Kiseleva IS, Noble D (1994) Mechanosensitive fibroblasts in the sino-atrial node region of rat heart: interaction with cardiomyocytes and possible role. Exp Physiol 79:943-956

27. Bruegmann T, Boyle PM, Vogt CC et al (2016) Optogenetic defibrillation terminates ventricular arrhythmia in mouse hearts and human simulations. JClin Invest 126:3894-3904

28. Crocini C, Ferrantini C, Coppini R et al (2016) Optogenetics design of mechanistically-based stimulation patterns for cardiac defibrillation. Sci Rep. https://doi.org/10.1038/srep35628

29. Nyns ECA, Kip A, Bart Cl et al (2016) Optogenetic termination of ventricular arrhythmias in the whole heart: towards biological cardiac rhythm management. Eur Heart J 38:2132-2136

30. Klimas A, Ambrosi CM, Yu J et al (2016) OptoDyCE as an automated system for high-throughput alloptical dynamic cardiac electrophysiology. Nat Commun 7:11542

31. Dempsey GT, Chaudhary KW, Atwater N et al (2016) Cardiotoxicity screening with simultaneous optogenetic pacing, voltage imaging and calcium imaging. JPharmacol Toxicol Methods 81:240-250

32. Chang Y-F, Broyles CN, Brook FA et al (2017) Noninvasive phenotyping and drug testing in single cardiomyocytes or beta-cells by calcium imaging and optogenetics. PLOSONE 12:e174181

33. Rincon MY, VandenDriessche T, Chuah MK (2015) Gene therapy for cardiovascular disease: advances in vector development, targeting, and delivery for clinical translation. Cardiovasc Res 108:4-20

34. Karathanos TV, Boyle PM, Trayanova NA (2016) Light-based approaches to cardiac arrhythmia research: from basic science to translational applications. Clin Med Insights Cardiol 10:47-60 